\title{
Nanoscale
}

A) Check for updates

Cite this: Nanoscale, 2019, 11, 6939

Received 14th November 2018,

Accepted 14th February 2019

DOI: $10.1039 / c 8 n r 09205 b$

rsc.li/nanoscale

\section{A template-free and low temperature method for the synthesis of mesoporous magnesium phosphate with uniform pore structure and high surface area†}

\author{
Jörn Hövelmann, (D) *a Tomasz M. Stawski, (D) a Rogier Besselink, ${ }^{a, b}$ \\ Helen M. Freeman, ${ }^{a, c}$ Karen M. Dietmann, ${ }^{d}$ Sathish Mayanna, ${ }^{a}$ Brian R. Pauw ${ }^{e}$ and \\ Liane G. Benning a,f,g
}

\begin{abstract}
Mesoporous phosphates are a group of nanostructured materials with promising applications, particularly in biomedicine and catalysis. However, their controlled synthesis via conventional template-based routes presents a number of challenges and limitations. Here, we show how to synthesize a mesoporous magnesium phosphate with a high surface area and a well-defined pore structure through thermal decomposition of a crystalline struvite $\left(\mathrm{MgNH}_{4} \mathrm{PO}_{4} \cdot 6 \mathrm{H}_{2} \mathrm{O}\right)$ precursor. In a first step, struvite crystals with various morphologies and sizes, ranging from a few micrometers to several millimeters, had been synthesized from supersaturated aqueous solutions (saturation index (SI) between 0.5 and 4) at ambient pressure and temperature conditions. Afterwards, the crystals were thermally treated at $70-250{ }^{\circ} \mathrm{C}$ leading to the release of structurally bound water $\left(\mathrm{H}_{2} \mathrm{O}\right)$ and ammonia $\left(\mathrm{NH}_{3}\right)$. By combining thermogravimetric analyses (TGA), scanning and transmission electron microscopy (SEM, TEM), $\mathrm{N}_{2}$ sorption analyses and small- and wide-angle X-ray scattering (SAXS/WAXS) we show that this decomposition process results in a pseudomorphic transformation of the original struvite into an amorphous $\mathrm{Mg}$-phosphate. Of particular importance is the fact that the final material is characterized by a very uniform mesoporous structure with 2-5 nm wide pore channels, a large specific surface area of up to $300 \mathrm{~m}^{2} \mathrm{~g}^{-1}$ and a total pore volume of up to $0.28 \mathrm{~cm}^{3} \mathrm{~g}^{-1}$. Our struvite decomposition method is well controllable and reproducible and can be easily extended to the synthesis of other mesoporous phosphates. In addition, the so produced mesoporous material is a prime candidate for use in biomedical applications considering that magnesium phosphate is a widely used, non-toxic substance that has already shown excellent biocompatibility and biodegradability.

\footnotetext{
${ }^{a}$ German Research Centre for Geosciences (GFZ), Interface Geochemistry, 14473 Potsdam, Germany. E-mail: jhoevelm@gfz-potsdam.de

${ }^{b}$ Université Grenoble Alpes, CNRS, ISTerre, Grenoble 38000, France

${ }^{c}$ School of Chemical and Process Engineering, University of Leeds, Leeds LS2 9JT, UK ${ }^{d}$ GIR-QUESCAT, Department of Inorganic Chemistry, University of Salamanca, 37008 Salamanca, Spain

${ }^{e}$ Federal Institute for Materials Research and Testing (BAM), 12205 Berlin, Germany ${ }^{f}$ Department of Earth Sciences, Freie Universität Berlin, 12249 Berlin, Germany ${ }^{g}$ School of Earth and Environment, University of Leeds, Leeds LS2 9JT, UK $\dagger$ Electronic supplementary information (ESI) available: XRD and Raman analyses of as-synthesized and thermally treated struvite samples; additional SEM images, TEM images, EDX and EELS spectra of the materials; comparison of $\mathrm{BJH}$ pore size distributions calculated from $\mathrm{N}_{2}$ adsorption $v s$. desorption data; additional time-resolved SAXS patterns of struvite decomposed under vacuum at $40{ }^{\circ} \mathrm{C}$. See DOI: $10.1039 / \mathrm{c} 8 \mathrm{nr} 09205 \mathrm{~b}$
}

\section{Introduction}

In the past decades, the synthesis of nanostructured materials with high surface area and porosity has become a major field of research. In particular, materials with a well-defined mesoporous structure (i.e., with pores of $2-50 \mathrm{~nm}$, according to IUPAC definition ${ }^{1}$ ) have attracted great interest because of their extremely wide-ranging applications, e.g., in catalysis, ${ }^{2}$ sorption, ${ }^{3}$ gas-sensing, ${ }^{4}$ energy storage, ${ }^{5}$ waste water treatment ${ }^{6}$ or biomedicine. ${ }^{7}$ To date, the vast majority of mesoporous materials are synthesized through a templating route. ${ }^{8}$ Such a synthesis route relies on surfactants to form micelles in the synthesis solution that self-assemble into ordered arrangements, i.e., the template, around which the solid material is deposited. In a final step, the organic template is removed by chemical etching or thermal treatment leaving behind a rigid 
porous structure. Since the first template-based synthesis of mesoporous silica in $1992,{ }^{9}$ great efforts have been devoted to extending the range of chemical compositions of mesoporous materials.

Among the various non-siliceous mesoporous materials, mesoporous phosphates are gaining increasing attention, especially because of their high potential for applications in biomedicine and catalysis. Mesoporous phosphates are highly bioactive and biocompatible, ${ }^{10-14}$ the two most important pre-requisites for applications in drug delivery systems or bone tissue engineering. Moreover, the facile functionalization of $\mathrm{PO}_{4}$ and/or $\mathrm{P}-\mathrm{OH}$ groups through organic or inorganic molecules could offer versatile options for tailoring their surface properties. ${ }^{15}$ Porous transition metal phosphates, in particular those of $\mathrm{Ti}$ and $\mathrm{Zr}$, have already shown great potential for catalytical applications due to the presence of abundant active metal sites on the pore surfaces. ${ }^{15-18}$ Although the chemical diversity of mesoporous phosphates has been expanding during the last years, their templatebased synthesis still bears significant problems and challenges that restrict further development. A major problem relates to the high reactivity of the inorganic phosphate precursors towards hydrolysis and condensation. This makes it difficult to control suitable interaction between micelles and the inorganic precursors, often preventing the formation of well-ordered mesostructured phosphate materials with controlled dimensions and morphologies. ${ }^{15}$ Another challenge is the conservation of the material's mesoporous structure after removal of the organic template. High temperature calcination or treatment with strong acids often results in serious degradation of the phosphate mesostructure. Milder acidethanol extraction, on the other hand, typically leads to incomplete removal of surfactant molecules. ${ }^{15}$ Furthermore, the presence of these often toxic residues severely restricts the application of the mesoporous phosphates in certain areas, particularly in biomedicine. Thus, the development of new strategies for synthesizing mesoporous phosphates is of great interest for both scientific research and technology development. Here, we present a template-free, low temperature method for the shape- and size-controlled synthesis of a mesoporous magnesium phosphate with a very large surface area and narrow pore size distribution. Our method involves the controlled thermal decomposition of a room temperature synthesized crystalline struvite precursor $\left(\mathrm{MgNH}_{4} \mathrm{PO}_{4} \cdot 6 \mathrm{H}_{2} \mathrm{O}\right)$ at $70-250{ }^{\circ} \mathrm{C}$. The precursor material, struvite, is a wellknown mineral that readily precipitates as orthorhombic crystals from supersaturated aqueous solutions at ambient temperatures and pressures. It is well known that when heated to temperatures above $55{ }^{\circ} \mathrm{C}$ struvite starts decomposing by releasing water $\left(\mathrm{H}_{2} \mathrm{O}\right)$ and ammonia $\left(\mathrm{NH}_{3}\right)$ from its structure. ${ }^{19-22}$ However, by using a combination of state-ofthe art characterization techniques we show for the first time that this decomposition process results in a highly porous and ordered magnesium phosphate nanostructure that retains the original 3D morphology of the primary struvite crystal.

\section{Materials and methods}

\subsection{Precursor material synthesis and decomposition}

Reagent grade $\mathrm{MgCl}_{2} \cdot 6 \mathrm{H}_{2} \mathrm{O}$ and $\left(\mathrm{NH}_{4}\right)_{2} \mathrm{HPO}_{4}$ (Sigma Aldrich) were used as starting salts for aqueous synthesis of the struvite precursor, following the reaction:

$$
\begin{aligned}
& \mathrm{Mg}^{2+}(\mathrm{aq})+\mathrm{HPO}_{4}{ }^{2-}(\mathrm{aq})+\mathrm{NH}_{4}{ }^{+}(\mathrm{aq}) \\
& \rightarrow \mathrm{MgNH}_{4} \mathrm{PO}_{4} \cdot 6 \mathrm{H}_{2} \mathrm{O}(\mathrm{s}) \downarrow+\mathrm{H}^{+}(\mathrm{aq})
\end{aligned}
$$

Solutions of each salt were prepared by dissolving proper amounts into double-deionized water (resistivity $>18 \mathrm{M} \Omega \mathrm{cm}$ ). The typical synthesis procedure was as follows: $100 \mathrm{ml}$ of a $100 \mathrm{mM}\left(\mathrm{NH}_{4}\right)_{2} \mathrm{HPO}_{4}$ solution was poured into a $500 \mathrm{ml}$ glass reactor and vigorously stirred at room temperature. Then $100 \mathrm{ml}$ of a $100 \mathrm{mM} \mathrm{MgCl} \cdot 6 \mathrm{H}_{2} \mathrm{O}$ solution was quickly added under continuous stirring. The mixed solution thus had and initial concentration of $c(\mathrm{Mg}, \mathrm{P})_{\text {mix }}=50 \mathrm{mM}$. Upon mixing, fine particles of a white precipitate quickly formed and the $\mathrm{pH}$ decreased from $c a .8$ to values between 5 and 6 due to the accompanying release of protons (eqn (1)). The suspension was kept stirring for several hours to ensure that equilibrium was attained. Thereafter, the particles were collected by vacuum filtration through a $0.2 \mu \mathrm{m}$ polycarbonate membrane and washed 3 times with $50 \mathrm{ml}$ of deionized water to remove any residual salts. Finally, the powder was left to dry in air at room temperature. Syntheses were also performed at other initial concentrations and $\mathrm{pH}$ values (adjusted with either $\mathrm{HCl}$ or $\mathrm{NaOH}$ ) to test for the effect on crystal morphology, size and phase purity (Table $\mathrm{S} 1 \dagger$ ). In addition, we also prepared larger, $\mathrm{mm}$-sized struvite single crystals by using a modified counterdiffusion method. For this, $1 \mathrm{M}$ solutions of $\left(\mathrm{NH}_{4}\right)_{2} \mathrm{HPO}_{4}$ and $\mathrm{MgCl}_{2} \cdot 6 \mathrm{H}_{2} \mathrm{O}$ were filled into separate $100 \mathrm{ml}$ glass beakers that were placed at opposite sides of a 61 plastic box. The plastic box was then carefully filled with deionized water until the two beakers were fully immersed. Finally, the box was closed with a lid to avoid evaporation and exchange with atmospheric $\mathrm{CO}_{2}$. Elongated, rod-like crystals started to form at the bottom of the plastic container after a few days and had been left to grow for about 2 weeks until they reached sizes of several millimetres. Thereafter, the crystals were removed from the solution, rinsed with water and dried in air at room temperature.

Following synthesis, struvite crystals were thermally treated in a drying oven at $70-250{ }^{\circ} \mathrm{C}$ for time periods ranging from $5 \mathrm{~min}$ to up to $180 \mathrm{~min}$. Each sample aliquot was weighed before and after heat treatment to calculate the relative weight loss. Selected runs were performed in duplicate to check for reproducibility (Table 1).

\subsection{Material characterization}

X-ray diffraction (XRD) patterns were collected on a PANanlytical Empyrean X-ray diffractometer using a $\mathrm{Cu} \mathrm{K} \alpha$ radiation source operating at $40 \mathrm{kV}$ and $40 \mathrm{~mA}$. Data were collected in the $2 \theta$ range between 4.6 and $85^{\circ}$ using a step size of $0.013^{\circ}$ and a counting time of $60 \mathrm{~s}$ per step. 
Table 1 Mass losses, BET surface areas and BJH pore parameters of struvite powders after thermal treatment

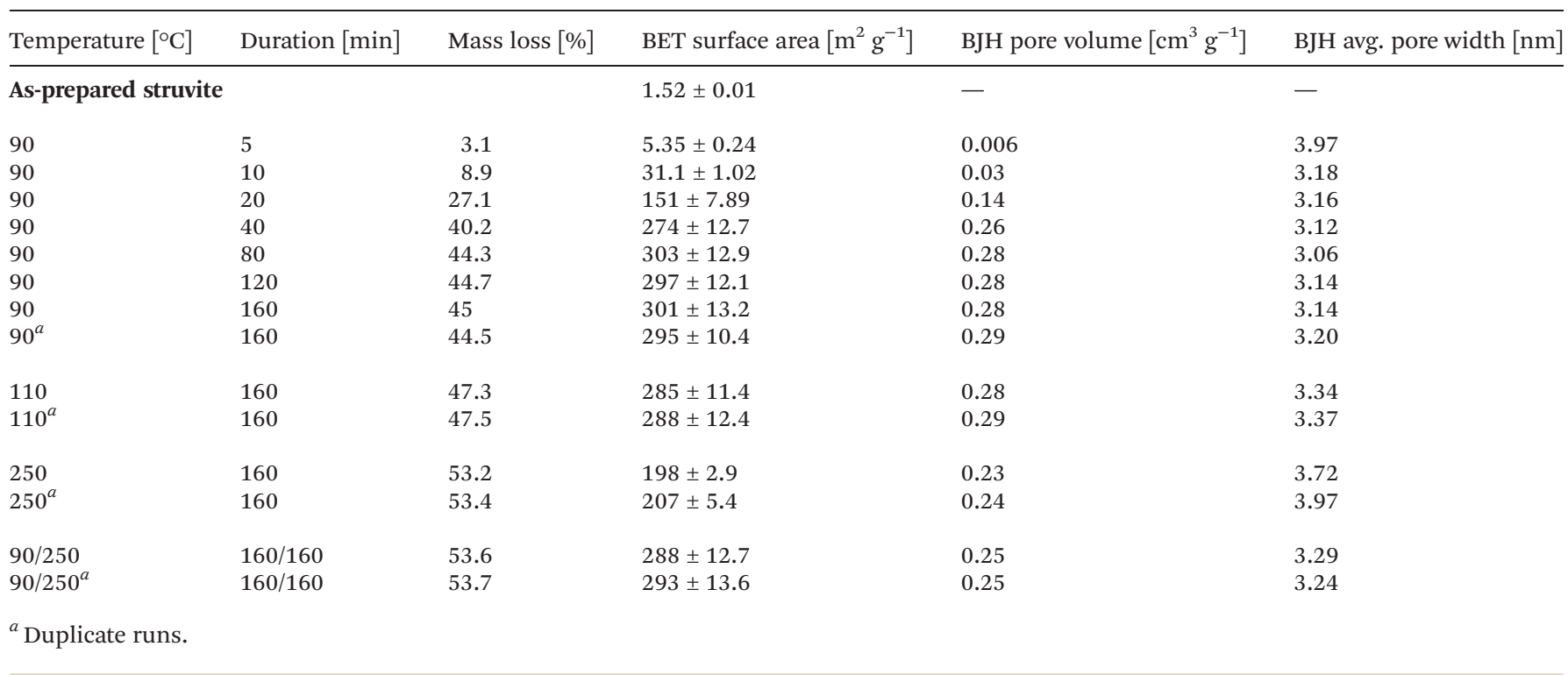

Raman spectroscopic analyses were performed using a confocal Raman spectrometer (LabRAM HR Evolution, Horiba Jobin Yvon) operating with the $532 \mathrm{~nm}$ line of a frequencydoubled Nd:YAG solid state laser. Spectra in the range of 250 and $1200 \mathrm{~cm}^{-1}$ were obtained with a $100 \times$ objective lens, a $50 \mu \mathrm{m}$ pinhole, and a grating of 1800 grooves per mm using an acquisition time $3 \times 30 \mathrm{~s}$. A reference spectrum of struvite was obtained from The RRUFF ${ }^{\mathrm{TM}}$ Project database. ${ }^{23}$

Scanning electron microscopy (SEM) images were recorded using an Ultra 55 Plus (Carl Zeiss SMT) field emission scanning electron microscope. A low acceleration voltage (1-3 kV) was used to limit the electron penetration depth and allow for resolving fine surface structures. All samples were coated with a $20 \mathrm{~nm}$-thick layer of carbon before imaging.

Cryo-SEM investigations were performed by placing $1 \mathrm{ml}$ of a freshly prepared struvite suspension into an Eppendorf tube and subsequent plunge freezing in a liquid nitrogen bath. The frozen sample was removed from the Eppendorf tube and fractured in a pre-cooled $\left(-180{ }^{\circ} \mathrm{C}\right)$ polystyrene box containing a metal base. The fractured sample was placed on the cryo sample holder and then transferred to the SEM using a BALTEC cryo transfer module.

Transmission electron microscopy (TEM) images were collected on a TECNAI F20 XTWIN TEM operated at $200 \mathrm{kV}$ with a field emission gun electron source, a Gatan Imaging Filter (GIF) Tridiem ${ }^{\mathrm{TM}}$, an EDAX X-ray analyzer, and a Fishione HAADF detector. Bright-field (BF) and dark-field (DF) images as well as high-resolution images were acquired as energy-filtered images. For that purpose, a $20 \mathrm{eV}$ window was applied to the zero-loss peak. Samples for TEM were prepared using a focused ion beam (FIB) and supported on a holey amorphous carbon coated $\mathrm{Cu}$ grid.

Simultaneous measurements of weight change (TGA) and differential heat flow (DSC) were carried out on dry struvite samples using a SDT Q600 TA Instruments device.
Additionally, the device was coupled to a GSD 301 T2 ThermoStar mass spectrometer (MS) in order to analyze the gases released during the thermal decomposition of the samples. All measurements were carried out under nitrogen atmosphere with a purge gas flow of $50 \mathrm{ml} \mathrm{min}^{-1}$. As a reference material for the heat flux DSC $\alpha-\mathrm{Al}_{2} \mathrm{O}_{3}$ was used. The samples were heated from room temperature to $250{ }^{\circ} \mathrm{C}$ using a heating rate of $1^{\circ} \mathrm{C} \mathrm{min}^{-1}$.

Nitrogen adsorption/desorption isotherms at $77 \mathrm{~K}$ were measured on a Micromeritics Gemini VII 2390t surface area and porosity analyser. The specific surface areas were determined by applying the BET (Brunauer-Emmett-Teller) equation to the relative pressure range $0.05-0.3$ for the adsorption branch of the isotherm. Pore volume and pore size distribution (PSD) plots were obtained by applying the BJH (BarrettJoyner-Halenda) method. BET and BJH calculations were performed with the Gemini VII Version 3.04 software delivered with the analysis equipment.

In situ and time-resolved small- and wide-angle X-ray scattering (SAXS/WAXS) measurements were carried out at beamline I22 of the Diamond Light Source Ltd (UK). Experiments were performed using a monochromatic X-ray beam at 12.4 $\mathrm{keV}$ and two-dimensional scattered intensities were collected at small-angles with a Dectris Pilatus P3-2M and at wideangles with Dectris Pilatus P3-2M-DLS-L (2D large area pixelarray detectors). Transmission was measured by means of a photodiode installed in the beam-stop of the SAXS detector. A sample-to-detector distance of $2.9 \mathrm{~m}$ allowed for a usable $q$-range of $0.005<q<\sim 0.35 \AA^{-1}$ in SAXS. The scattering-range at small-angles was calibrated against silver behenate and the corresponding measured intensity was calibrated to absolute units against glassy carbon. The $q$-range in WAXS was calibrated with cerium(Iv) oxide powder. The sample powders were loaded into borosilicate capillaries of an external diameter of $1.5 \mathrm{~mm}$ and a wall-thickness of $10 \mu \mathrm{m}$ and measured in a 
movable capillary rack aligned with the X-ray beam. We also measured the required backgrounds, including an empty capillary, and a no-sample beamline background. The recorded 2D SAXS patterns were found to be independent of the in-plane azimuthal angle with respect to the detector (i.e., scattering patterns where circular in shape), showing that the investigated systems could be considered isotropic. In those patterns, pixels corresponding to similar $q$-values were averaged over all azimuthal angles, and hence the $2 \mathrm{D}$ patterns were reduced to 1D curves. SAXS data processing and reduction included primarily masking of undesired pixels, normalizations and correction for transmission, background subtraction and data integration to $1 \mathrm{D}$ for which we followed a procedure described by Pauw et $a .^{24}$ The recorded 2D WAXS patterns were corrected for background in the same way as the SAXS patterns, but were not converted to $1 \mathrm{D}$ curves. All these steps were performed using the Data Analysis WorkbeNch (DAWN) software package (v. 2.6+) according to I22 guidelines.

Additional SAXS measurements were performed in the laboratory on an Anton Paar SAXSess slit-collimated instrument, using multilayer-mirror-monochromatized copper $\mathrm{K} \alpha$ radiation, and modified to use a Dectris Mythen photon-counting strip detector. The measurements consist of 65 repetitions of 120 10-second frames (total duration 22 hours), with the sample held at a temperature of $40{ }^{\circ} \mathrm{C}$. The sample was mounted at the sample position inside the SAXSess vacuum chamber, uniformly distributed in a sandwich of Scotch ${ }^{\circledR}$ Magic Tape. The data have been corrected for exposure time, darkcurrent, transmission, background, absolute units scaling, and deconvoluted for slit-smearing effects. The data was scaled to absolute units using water scattering as a reference, and with the required apparent struvite sample thickness derived from the transmission factor of the struvite component, and the X-ray absorption coefficient of the sample. The transmission factor was accurately determined using the fluorescence ratio from a 10 micron iron foil in the sampleattenuated and direct beam, respectively (due to significant radiation hardening by the semi-transparent beamstop, transmission values derived from quantification of the beamstopattenuated beam are incorrect). The $q$-scale was calibrated using the instrument geometry and stated detector pixel size, and has been verified using silver behenate.

\section{Results and discussion}

\subsection{Characterization of as-synthesized struvite}

The as-prepared struvite powders were highly crystalline as evidenced by the XRD patterns (Fig. S1A and B†). The obtained XRD patterns match the reference patterns for struvite (ICSD 98-001-4269) with no additional peaks demonstrating the high purity of the synthesized material. The struvite crystals synthesized from mixed solutions with high initial concentrations $\left(c(\mathrm{Mg}, \mathrm{P})_{\text {mix }}=50 \mathrm{mM}\right)$ at $\mathrm{pH} 8$ were $100-200 \mu \mathrm{m}$ in size and showed mainly dendritic or X-shaped morphologies (Fig. 1A), reflecting their fast nucleation and growth. ${ }^{25}$ In contrast, the slow counter-diffusion synthesis resulted in elongated, lathshaped crystals (up to $7 \mathrm{~mm}$ long and 1-2 mm wide) with welldefined faces and straight edges (Fig. 1B). These crystals were confirmed as struvite based on their Raman spectra (Fig. S1C $\dagger$ ). Syntheses performed at lower concentrations $\left(c(\mathrm{Mg}, \mathrm{P})_{\text {mix }}=15-25 \mathrm{mM}\right)$ and a $\mathrm{pH}$ of 6.7 also resulted in wellfaceted struvite crystals showing the typical blocky or coffinlike forms (Fig. 1C-E). When observed under the SEM, the struvite crystals often showed a nanogranular morphology as well as a large number of Y- and cross-shaped gaps or cracks at the surface, ranging in width from tens to hundreds of nanometers (Fig. 1C and D). To verify whether these features were formed during crystal growth or within the SEM due to the high vacuum or electron beam damage, we performed cryoSEM investigations of some freshly prepared struvite crystals. Under cryogenic conditions, the crystal surfaces were flat and smooth with no visible gaps, as would indeed be expected for natural growth surfaces (Fig. 1E). Hence, it is apparent that the surface features observed under conventional room temperature/high vacuum SEM imaging conditions are artefacts, most likely related to (partial) de-volatilization of the struvite. This hypothesis is supported by results from FIB-TEM investigations of one of the struvite crystals (Fig. S2 $\dagger$ ). The TEM images again revealed lots of cracks as well as a high internal porosity (Fig. S2A and $\mathrm{B} \dagger$ ). Interestingly, no lattice fringes were observed in high resolution TEM images (HRTEM) (Fig. S2C $\dagger$ ) indicating that the struvite crystal imaged was likely transformed into an amorphous material in the TEM. Although, energy dispersive X-ray (EDX) analyses of the material confirmed the presence of $\mathrm{Mg}$ and $\mathrm{P}$ (Fig. S2D $\dagger$ ), the electron energy loss spectroscopy (EELS) showed only a very weak $\mathrm{N}$ K-edge that disappeared completely after several minutes of beam exposure (Fig. S2E and $\mathrm{F} \dagger$ ). Overall, these observations indicate that struvite crystals readily decomposed even at room temperature when exposed to the high vacuum of an SEM or TEM.

\subsection{Thermal decomposition of struvite}

Following the thermal decomposition of the precursor material with TGA/DSC (Fig. 2A) revealed that struvite started decomposing at a temperature of around $50{ }^{\circ} \mathrm{C}$, which is in agreement with previous reports. ${ }^{19-22}$ A major mass loss step of $\sim 43 \%$ occurred between 50 and $90{ }^{\circ} \mathrm{C}$. This was followed by a more gradual mass loss between 90 and $250{ }^{\circ} \mathrm{C}$. The total (final) mass loss obtained at $250{ }^{\circ} \mathrm{C}$ was about $54 \%$, which is close the theoretical value of $54.6 \%$ for the complete de-volatilization of struvite and the formation of $\mathrm{Mg}$-pyrophosphate $\left(\mathrm{Mg}_{2} \mathrm{P}_{2} \mathrm{O}_{7}\right)$ according to the reaction:

$$
\mathrm{MgNH}_{4} \mathrm{PO}_{4} \cdot 6 \mathrm{H}_{2} \mathrm{O}(\mathrm{s}) \rightarrow \frac{1}{2} \mathrm{Mg}_{2} \mathrm{P}_{2} \mathrm{O}_{7}(\mathrm{~s})+\mathrm{NH}_{3} \uparrow+6.5 \mathrm{H}_{2} \mathrm{O} \uparrow
$$

The DSC curve shows only a single, broad endothermic peak at ca. $90{ }^{\circ} \mathrm{C}$ (Fig. 2A). This peak corresponds to the major $43 \%$ mass loss during heating. The presence of a single peak in the DSC curve indicates that water and ammonia were lost 

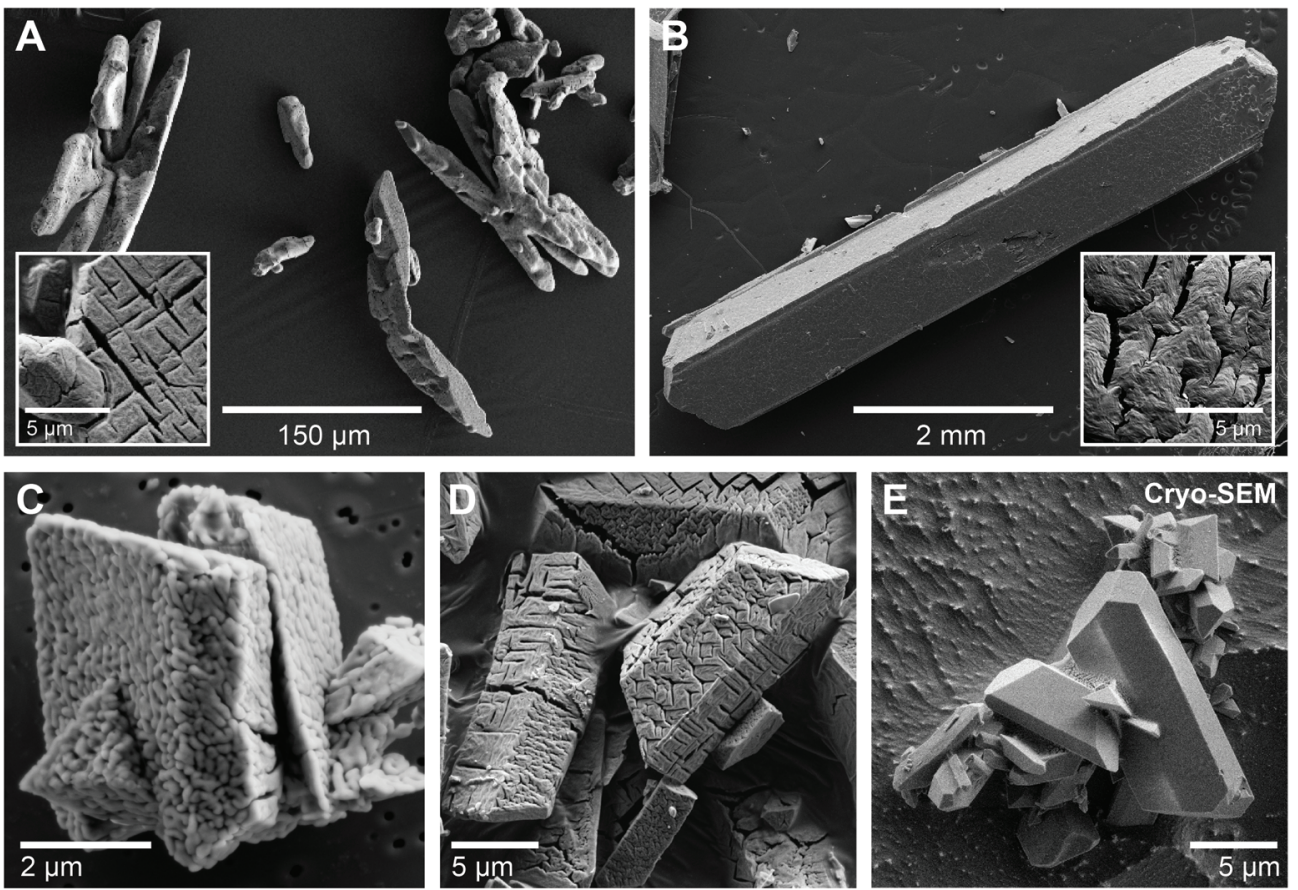

Fig. 1 SEM images of struvite crystals as-synthesized at room temperature. (A) Medium sized dendritic, X-shaped struvite crystals synthesized by fast solution mixing at an initial concentration of $c(\mathrm{Mg}, \mathrm{P})_{\text {mix }}=50 \mathrm{mM}(\mathrm{pH}$ 8); inset: crystal surface imaged at higher magnification. (B) Large, millimeter-sized, lath-shaped struvite crystal synthesized by slow counter-diffusion method (see section 2.1 for details); inset: crystal surface imaged at higher magnification. (C-E) Smaller blocky, coffin-like struvite crystals synthesized at $\mathrm{pH} 6.7$ by fast solution mixing using initial solution concentrations $\left(c(\mathrm{Mg}, \mathrm{P})_{\text {mix }}\right.$ ) of (C) $15 \mathrm{mM},(\mathrm{D}) 20 \mathrm{mM}$ and (E) $25 \mathrm{mM}$. Crystals in (A-D) were imaged using conventional room temperature/high vacuum SEM conditions; they show nanogranular morphologies and abundant surface cracks. In contrast, crystals in (E) were imaged under cryogenic conditions and show flat and smooth surfaces.

A
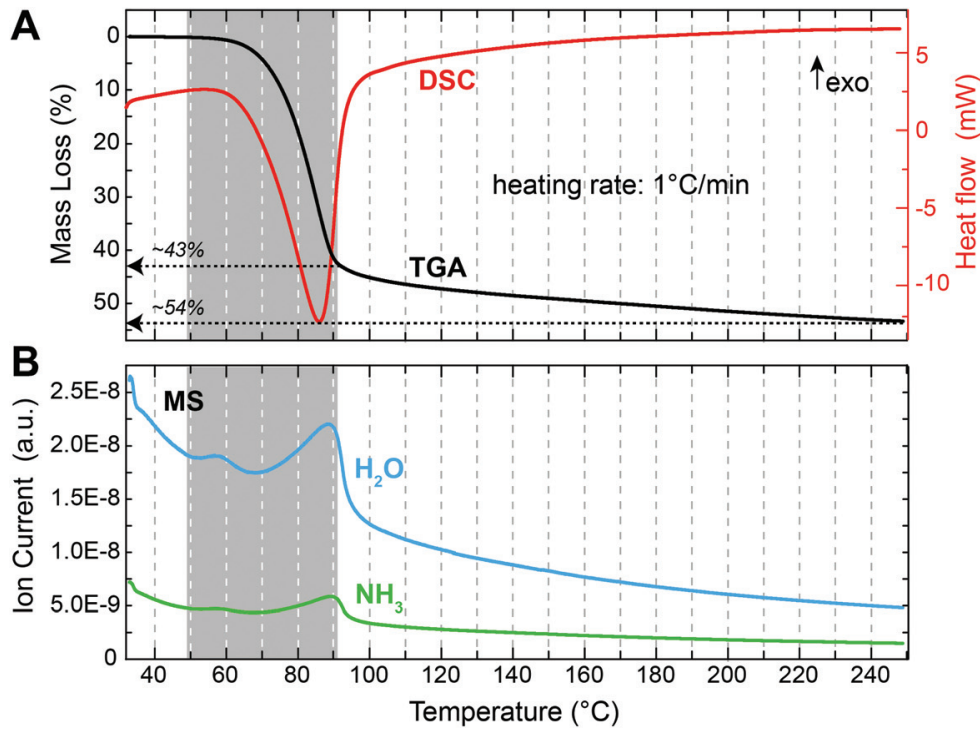

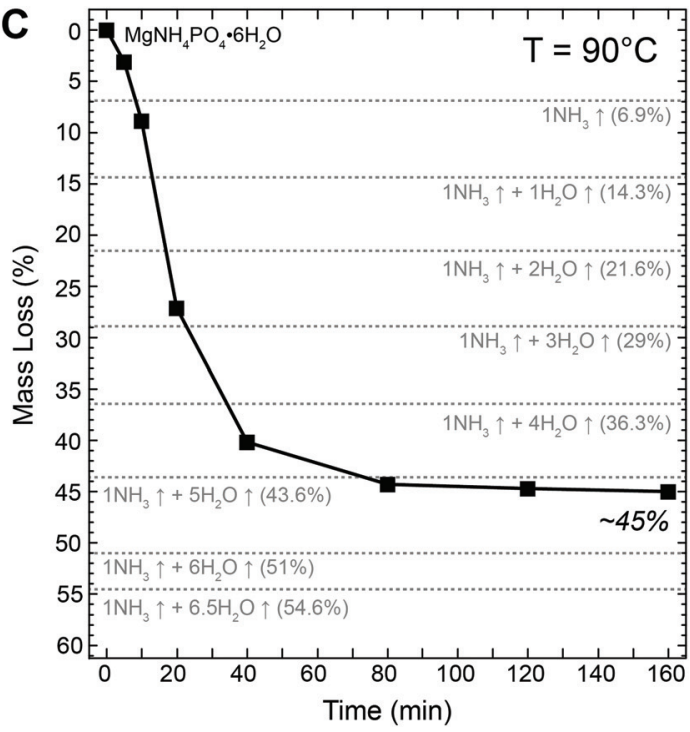

Fig. 2 (A) TGA (black) and DSC (red) curves of struvite for a heating rate of $1{ }^{\circ} \mathrm{C} \mathrm{min}^{-1}$ from $30-250{ }^{\circ} \mathrm{C}$. (B) Corresponding MS data showing the evolution of $\mathrm{H}_{2} \mathrm{O}$ (blue) and $\mathrm{NH}_{3}$ (green) releases. Grey areas in $\mathrm{A}$ and $\mathrm{B}$ delineate the major mass loss step of $43 \%$ between 50 and $90{ }^{\circ} \mathrm{C}$. (C) Mass evolution during isothermal struvite decomposition at $90{ }^{\circ} \mathrm{C}$. Dotted lines represent theoretical mass losses for the release of $1 \mathrm{NH}_{3}$ and $0-6.5 \mathrm{H}_{2} \mathrm{O}$ molecules per structural formula. All measurements were performed on struvite crystals synthesized at room temperature by fast solution mixing at an initial concentration of $c(\mathrm{Mg}, \mathrm{P})_{\text {mix }}=50 \mathrm{mM}$ and an initial $\mathrm{pH}$ of 8. 
simultaneously from the struvite structure. Otherwise two distinct peaks should have been visible. This is corroborated by the corresponding MS data (Fig. 2B) where the releases of $\mathrm{NH}_{3}$ and $\mathrm{H}_{2} \mathrm{O}$ occurred simultaneously at temperatures between 50 and $90{ }^{\circ} \mathrm{C}$. Measuring the mass evolution under isothermal conditions at $90{ }^{\circ} \mathrm{C}$ reveals that the mass loss was initially fast, reaching about $40 \%$ within the first $40 \mathrm{~min}$, but then slowed down considerably and stabilized at $44-45 \%$ after about 80 min (Fig. 2C and Table 1). This mass loss is close to what would be expected for the loss of $1 \mathrm{NH}_{3}$ and $5 \mathrm{H}_{2} \mathrm{O}$ molecules from the initial $\mathrm{MgNH}_{4} \mathrm{PO}_{4} \cdot 6 \mathrm{H}_{2} \mathrm{O}$ structure resulting in the formation of $\mathrm{MgHPO}_{4} \cdot \mathrm{H}_{2} \mathrm{O}$. However, we cannot exclude that some residual $\mathrm{NH}_{4}$ is still present in the decomposition product at this point. Nevertheless, this analysis shows that any further mass loss is temperature- rather than timedependent.

\subsection{Structural evolution during struvite decomposition}

Thermal decomposition of struvite at temperatures up to $250{ }^{\circ} \mathrm{C}$ resulted in the formation of an amorphous material as shown by XRD analyses (Fig. S3†). During this transformation the initially transparent struvite crystals turned opaque white, but retained their original crystal shapes. Fig. 3A shows an SEM image of a larger, mm-sized struvite crystal that was thermally treated at $70{ }^{\circ} \mathrm{C}$ for 3 hours. Despite the heat treatment the typical faceted morphology of the original struvite crystal (cf. Fig. 1B) was preserved. However, a more detailed view revealed abundant cracks at the crystal surface, ranging between $0.1-1 \mu \mathrm{m}$ in width and 1-10 $\mu \mathrm{m}$ in length (Fig. 3B and $\mathrm{C}$ ). The cracks often branch out at their ends, but otherwise appear to follow a direction close to parallel to the crystal's long axis indicating that their propagation could have
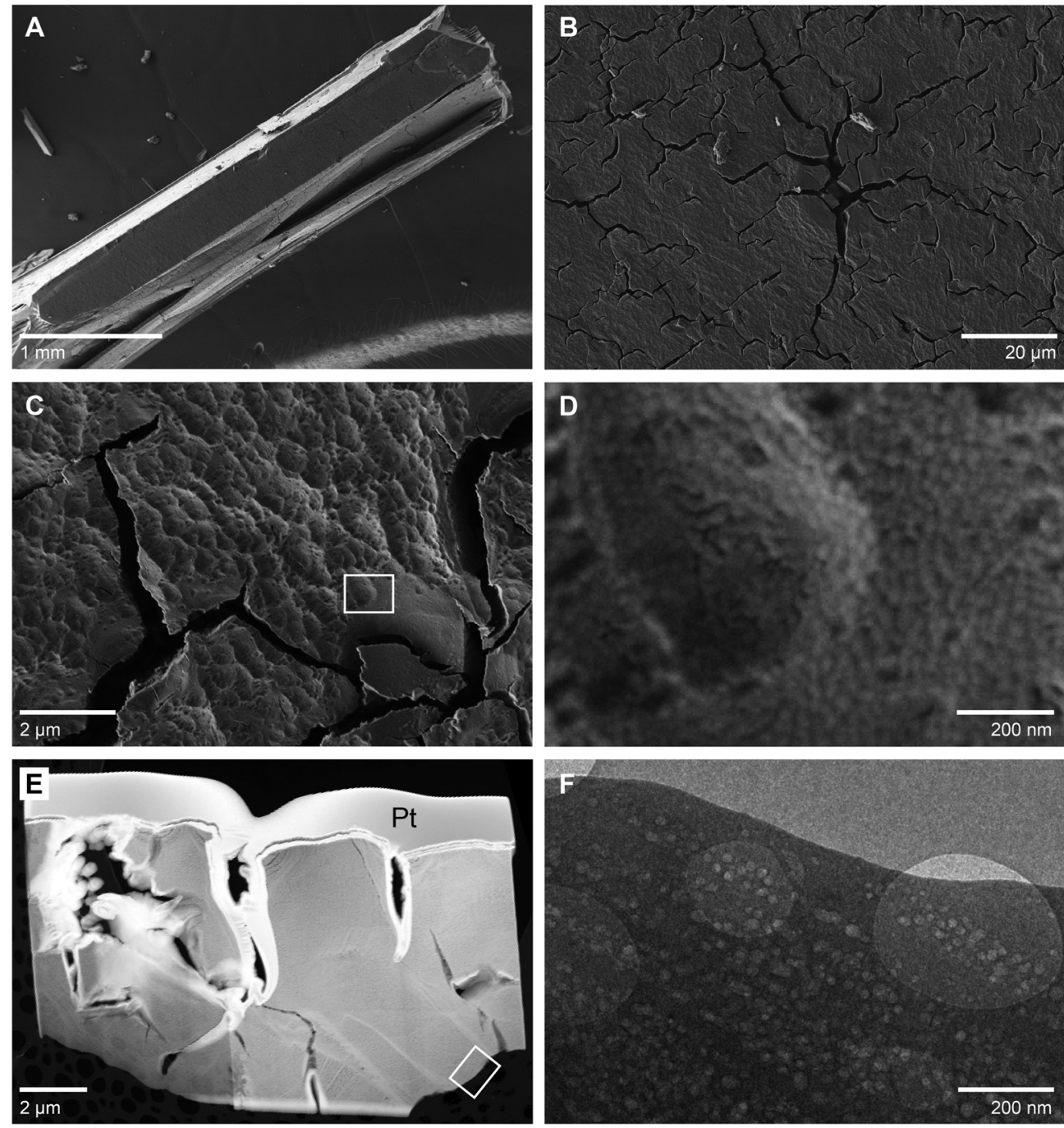

Fig. 3 (A) SEM image of a larger, mm-sized struvite crystal after heat-treatment at $70{ }^{\circ} \mathrm{C}$ for 3 hours. (B, C) Higher magnification images showing the presence of cracks and circular depressions at the surface. (D) Higher magnification image of the area marked in (C) by a white rectangle showing a nanogranular surface texture. (E) Scanning transmission electron microscopy (STEM) image of a FIB section prepared from the same crystal. (F) Bright field TEM image of the region indicated in (E) by a white rectangle revealing the highly porous nature of the decomposed material. 
occurred along specific crystal planes. The surface between the cracks is characterized by a high roughness, which is in contrast to the perfectly flat growth surfaces of the original crystals (Fig. 1E). At higher magnification, it becomes evident that this roughness results from multiple overlapping circular surface depressions (Fig. 3C) suggesting that the decomposed, yet morphologically still looking like struvite crystal, experienced some shrinkage during decomposition. Hence, it seems reasonable to assume that the formation of the cracks is also related to this shrinkage process and the concomitant generation of tensile stresses within the crystal. It was however noted already above (e.g., Fig. 1D) that similar cracks were also observed on non-heat treated struvite crystals. Nevertheless, the thermally decomposed struvite crystals showed a much lower crack density than the crystals that were only decomposed under high vacuum (Fig. S4†). This possibly suggests that the decomposition in high vacuum was more abrupt leading to more vigorous gas out-bursts and giving little time for relaxation by mechanisms other than cracking.

At a very high magnification $(>20000 \times)$ a nanogranular surface texture that appears to be composed of small spherical particles with diameters of about $20 \mathrm{~nm}$ becomes evident (Fig. 3D). The interstitial space between these nanoparticles appears essentially empty implying that there should be a large amount of porosity left in the decomposed material. The highly porous nature of the decomposed crystal was confirmed by TEM investigations of a FIB section (Fig. 3E and F) showing dense arrays of near-round pores with uniform sizes of approximately $20 \mathrm{~nm}$. We attempted to visualize the 3D shape and structure of these pores by acquiring multiple images of the same region in a tilt-series using tilt-steps of $1^{\circ}$ from $-70^{\circ}$ to $+70^{\circ}$. However, during imaging the pores widened considerably as a function of time (Fig. S5†), possibly due to an ongoing decomposition under the high vacuum or due to the sensitivity of the material to the electron beam.

To evaluate the temporal evolution of the development of this porosity as well as their characteristics, we performed $\mathrm{N}_{2}$ gas adsorption-desorption measurements on struvite samples that were thermally treated at $90{ }^{\circ} \mathrm{C}$ for time periods between 5 and $160 \mathrm{~min}$. Fig. $4 \mathrm{~A}$ shows the $\mathrm{N}_{2}$ adsorption-desorption isotherms obtained at $-196{ }^{\circ} \mathrm{C}$. All isotherms exhibit the same general shape with four well-defined stages: (i) at low relative pressures $\left(p / p_{0} \leq 0.25\right)$ a gradual increase in $\mathrm{N}_{2}$ uptake is observed and attributed to monolayer-multilayer adsorption on the pore walls, (ii) at intermediate relative pressure $(0.25 \leq$ $\left.p / p_{0} \leq 0.45\right)$ a prominent step occurred possibly due to capillary condensation within small pores, (iii) at high relative pressures $\left(0.45 \leq p / p_{0} \leq 0.95\right)$ a plateau region with a slight inclination is observed indicating the absence of larger pores (i.e., the slow $\mathrm{N}_{2}$ uptake in this region is due to multilayer adsorption of $\mathrm{N}_{2}$ molecules on the external surface of the particles), (iv) at very high relative pressures $\left(p / p_{0} \geq 0.95\right)$ a further steep increase occurred that can be assigned to bulk condensation of $\mathrm{N}_{2}$. The amount of $\mathrm{N}_{2}$ adsorbed increased strongly with increasing time. For example, plateau values were below $0.2 \mathrm{mmol} \mathrm{g}^{-1}$ after $5 \mathrm{~min}$ and $\sim 6.5 \mathrm{mmol} \mathrm{g}^{-1}$ after
80 min (i.e., $>30$-fold increase). No significant changes in the isotherms were observed for thermal treatment times longer than $\sim 80$ min.

The observed step on the isotherm at intermediate relative pressures (Fig. 4A) points to a type IV isotherm (in the IUPAC classification). This type of isotherm is typically observed for mesoporous materials (i.e., materials containing pores with diameters between 2 and $50 \mathrm{~nm}$ ) with the step being indicative of capillary condensation inside the pores - a phenomenon whereby vapour condenses to a liquid-like phase at pressures below the vapour saturation pressure $\left(p_{0}\right)$ of the bulk liquid. In the vast majority of systems, capillary condensation is associated with a pronounced hysteresis loop starting at values of $p /$ $p_{0} \approx 0.42 .^{26,27}$ For example, when gas adsorption occurs in perfectly cylindrical mesopores, capillary condensation occurs via a cylindrical meniscus separating the vapour from the condensed phase. However, during desorption capillary evaporation occurs via a hemispherical meniscus. This causes pores of a specific size to be filled at higher pressures and emptied at lower pressures, hence resulting in a hysteresis. In our case, however, no or very little hysteresis was observed in the isotherms (Fig. 4A) indicating that the pores were completely filled and emptied at similar pressures. In fact, the obtained isotherms are strikingly similar to those previously reported for some commercial silica-based mesoporous materials (e.g., Mobil Composition of Matter no. 41 (MCM-41) or Santa Barbara Amorphous no. 15 (SBA-15)) with well-defined and ordered cylindrical mesopores. ${ }^{28-30}$ For these mesoporous silicas it has been shown that the ad- and desorption isotherms become reversible (i.e., no hysteresis) if the pore diameters are tuned to values between 2 and $4 \mathrm{~nm}$. Nevertheless, a prominent step is still present on the isotherms of these materials demonstrating that capillary condensation is not inevitably accompanied by hysteresis. Hence, for small cylindrical mesopores $(2-4 \mathrm{~nm})$, there seems to exist a reversible capillary condensation regime ${ }^{27}$ that is intermediate between the regime of volume filling without condensation for very narrow pores $(\lesssim 2 \mathrm{~nm})$ and the irreversible capillary condensation regime for reasonably wide pores $(\gtrsim 4 \mathrm{~nm})$. In this intermediate regime the disappearance of the hysteresis is possibly related to a tensional instability of the hemispherical meniscus caused by an increased chemical potential of the pore walls. ${ }^{31}$ Such reversible type IV isotherms are typically referred to as type IVc. Given the fact that the isotherms shown in Fig. 4A reveal the typical characteristics of type IVc isotherms, we can infer that the pores in the struvite decomposition material have a fairly uniform, channel-like shape with a narrow, nearly constant diameter between 2 and $4 \mathrm{~nm}$. This conclusion was corroborated by the pore size distribution (PSD) analyses (Fig. 4B) derived by applying the Barrett-Joyner-Halenda (BJH) method. The PSDs reveal that the pore widths vary only over a relatively narrow range between 2 and $5 \mathrm{~nm}$ with a clear peak centred at 3.1-3.2 nm. PSDs derived from gas sorption isotherms can sometimes be affected by the so-called tensile strength effect (TSE), i.e., the spontaneous evaporation of metastable pore liquid. ${ }^{26,31}$ In such a case, isotherms typically 

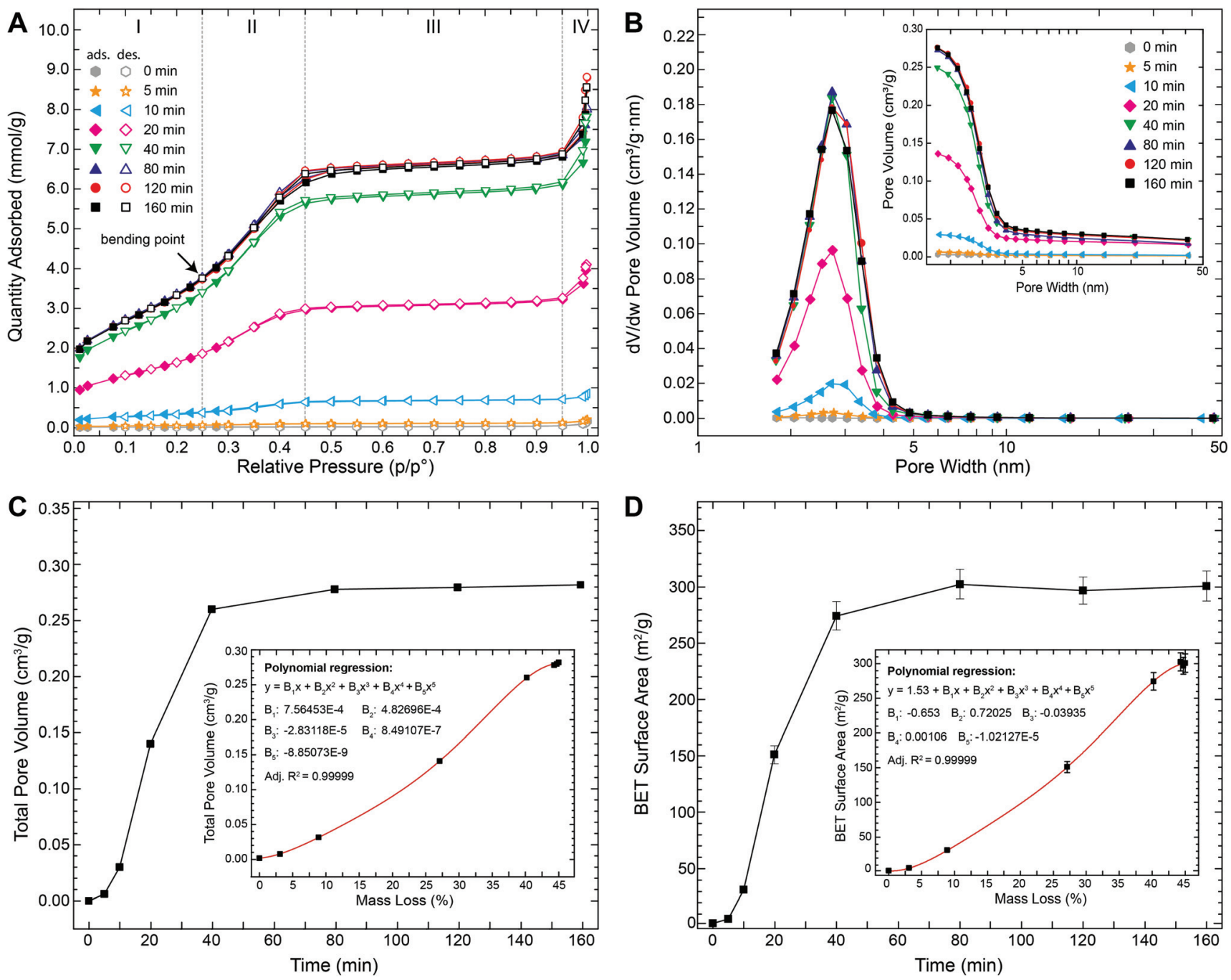

Fig. 4 Results from $\mathrm{N}_{2}$ gas sorption analyses of struvite powders after thermal treatment at $90{ }^{\circ} \mathrm{C}$ for $5-160$ min. (A) Adsorption-desorption isotherms (closed symbols: adsorption; open symbols: desorption). All isotherms have the same general shape with four well-defined stage (I-IV; delineated by vertical dotted lines) and a bending point at a relative pressure of $\sim 0.25$ (see main text for more detailed explanations). (B) Pore size distribution plots obtained by applying the BJH method; inset: cumulative pore size distributions. (C) Total pore volume as a function of thermal treatment time; inset: correlation between total pore volume and mass loss. (D) BET surface area as a function of thermal treatment time; inset: correlation between BET surface area and mass loss. Error bars indicate measurement errors reported by the Gemini VII Version 3.04 software.

display a clear hysteresis with a characteristic step-down ${ }^{26}$ in the desorption branch at $p / p_{0} \approx 0.45$ and an artificial peak near $3.8 \mathrm{~nm}^{31}$ only in the desorption-derived PSD and not in the adsorption-derived PSD. In our case, we can confidently exclude a TSE contribution to the PSD, because (i) no hysteresis was observed (Fig. 4A) and (ii) both adsorption- and desorption-derived PSDs gave nearly identical results with no artificial peak (Fig. S6 $\dagger$ ). It should be noted, however, that the $\mathrm{BJH}$ method commonly underestimates pore sizes by up to $20-30 \%$ for pores smaller than $10 \mathrm{~nm} .^{26}$ Thus, the "real" pore size may be up to $1 \mathrm{~nm}$ larger than the calculated values. In any case, this pore size is more than 5 times smaller than the pores observed in TEM (Fig. 3F). The larger pore sizes in TEM images are most likely due to an artificial pore widening possibly induced by the bombardment with Ga-ions during sample preparation and high-energy electrons during TEM observation and/or a continued material decomposition in the high vacuum. Indeed, such widening of pores was also directly observed during our attempt of tilt-series imaging in TEM (Fig. $\mathrm{S} 4 \dagger$ ). In contrast, our $\mathrm{N}_{2}$ gas sorption measurements demonstrate that the average pore width remained constant at 3.1-3.2 $\mathrm{nm}$ for up to $160 \mathrm{~min}$ during the thermal decomposition at $90{ }^{\circ} \mathrm{C}$ (Fig. $4 \mathrm{~B}$ and Table 1 ). The total pore volume, on the other hand, increased sharply within the first $40 \mathrm{~min}$ before reaching a stable maximal value of $\sim 0.28 \mathrm{~cm}^{3} \mathrm{~g}^{-1}$ after ca. 80 min (Fig. 4C and Table 1). Similarly, the BET surface area increased rapidly from $1.52 \mathrm{~m}^{2} \mathrm{~g}^{-1}$ (initial struvite) to $274.4 \mathrm{~m}^{2} \mathrm{~g}^{-1}$ with in the first $40 \mathrm{~min}$ and then reached a final stable value of $\sim 300 \mathrm{~m}^{2} \mathrm{~g}^{-1}$ after $80 \mathrm{~min}$ (Fig. 4D and Table 1). Both the total pore volume and the BET surface area show a 
strong positive correlation with total weight loss (insets in Fig. 4C+D).

In summary, our TGA/DSC/MS and gas sorption data demonstrate that the release of ammonia and water during the thermal decomposition of struvite led to the formation of a nanostructure featuring one of the largest surface areas $\left(300 \mathrm{~m}^{2} \mathrm{~g}^{-1}\right)$ and narrowest pore size distributions $(2-5 \mathrm{~nm})$ ever reported for a mesoporous phosphate. ${ }^{15}$ This nanostructure gradually formed through an initial nucleation of small pores at the crystal surfaces and their subsequent growth in depth and the formation of arrays of channel-like mesopores. The increase in total pore volume and BET surface area is solely due to a one-dimensional growth of these mesopore channels as evidenced by the development of a narrow and temporally highly constant pore size distribution. Lateral growth of pores would have caused a clear time-dependent shift in the PSDs and eventually also pore coalescence and thus a reduction in surface area (e.g., for perfectly parallel cylindrical pores the surface area would decrease by a factor of $n^{-1 / 2}$, where $n$ represents the number of coalescing pores). Within the experimental time frame $(160 \mathrm{~min})$, the nanostructural development is closely coupled to the decomposition process (i.e., the release of $\mathrm{H}_{2} \mathrm{O}$ and $\mathrm{NH}_{3}$ ), as evidenced by the parallel temporal evolution of pore volume, surface area and mass loss (Fig. $2 \mathrm{~B}+4 \mathrm{C}$ and D). At $90{ }^{\circ} \mathrm{C}$, the process is essentially completed after $80 \mathrm{~min}$. The observation that the pore volume and surface area remained constant at their maximum values even after continual heating for up to $160 \mathrm{~min}$, indicates no further secondary re-structuring (e.g., Ostwald ripening).

To investigate the effect of temperature on the surface area and porosity of the decomposition product we also performed thermal treatments at $110{ }^{\circ} \mathrm{C}$ and $250{ }^{\circ} \mathrm{C}$ (Table 1). As expected from our TGA data (Fig. 2A), these treatments resulted in somewhat higher mass losses $\left(\sim 47.5 \%\right.$ at $110{ }^{\circ} \mathrm{C}$ and $\sim 53.4 \%$ at $250{ }^{\circ} \mathrm{C}$ ). $\mathrm{N}_{2}$ gas adsorption analyses also revealed a slight temperature-dependent increase in average pore widths from 3.1-3.2 $\mathrm{nm}$ at $90{ }^{\circ} \mathrm{C}$ to $3.3-3.4 \mathrm{~nm}$ at $110^{\circ} \mathrm{C}$ and $3.7-4 \mathrm{~nm}$ at $250^{\circ} \mathrm{C}$. However, the BET surface areas and total pore volumes did not exceed the ones from the $90{ }^{\circ} \mathrm{C}$ samples. Samples treated at $110{ }^{\circ} \mathrm{C}$ had BET surface areas of $280-290 \mathrm{~m}^{2} \mathrm{~g}^{-1}$ and pore volumes of $\sim 0.28 \mathrm{~cm}^{3} \mathrm{~g}^{-1}$ and thus were similar to the $90{ }^{\circ} \mathrm{C}$ samples. In contrast, samples treated at $250{ }^{\circ} \mathrm{C}$ had significantly lower BET surface areas $\left(\sim 200 \mathrm{~m}^{2} \mathrm{~g}^{-1}\right)$ and pore volumes $\left(\sim 0.24 \mathrm{~cm}^{3} \mathrm{~g}^{-1}\right)$. On the other hand, when first treated at $90{ }^{\circ} \mathrm{C}$ and then at $250{ }^{\circ} \mathrm{C}$, the BET surface areas were again $\sim 290 \mathrm{~m}^{2} \mathrm{~g}^{-1}$, while pore volumes were $\sim 0.25 \mathrm{~cm}^{3} \mathrm{~g}^{-1}$.

The nanostructural evolution during the thermal decomposition of struvite at $90{ }^{\circ} \mathrm{C}$ was also followed by small- and wideangle X-ray scattering (SAXS/WAXS). Fig. 5A shows that the WAXS patterns collected from the 5-20 min heat treated samples contained several sharp and intense diffraction peaks in the $q$-range $0.8-3 \AA^{-1}$ that can be assigned to crystalline struvite. After $\sim 20$ minutes a clear decrease in intensity of the WAXS diffraction peaks with time is observed, while concomitantly two broad, gradually increasing local maxima start to develop at $\sim 1.6 \AA^{-1}$ and $2.2 \AA^{-1}$. The WAXS pattern of the (final) $160 \mathrm{~min}$ sample only shows a broad profile without any diffraction peaks, indicating the complete absence of longrange order (i.e., crystallinity) in the sample. From the WAXS data we can infer that the decomposition of struvite at $90{ }^{\circ} \mathrm{C}$ leads to the formation of an amorphous phase. The observed changes in the WAXS patterns (i.e., decreasing peak intensities and increasing broad local maxima heights) originate from the gradually decreasing volume fractions of struvite and the increase in the volume fraction of the amorphous phase. This struvite-to-amorphous transition does not appear to involve any intermediate crystalline phase as no diffraction peaks
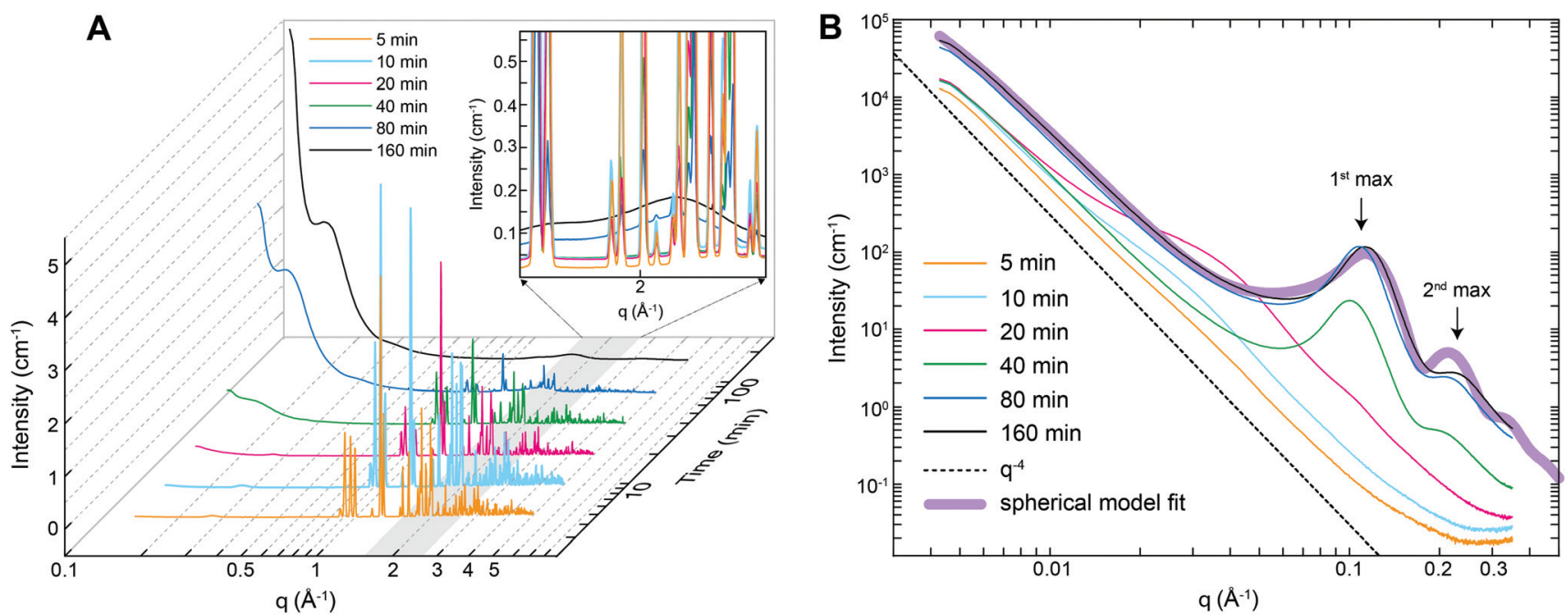

Fig. 5 (A) WAXS and (B) SAXS patterns of struvite powders after thermal treatment at $90{ }^{\circ} \mathrm{C}$ for $5-160$ min. Inset in (A) is a zoom-in into $q$-range $1.6-2.2 \AA^{-1}$. There are some intensity fluctuations in the WAXS diffraction peaks between 5 and 20 min that are likely related to crystal orientation effects caused by an inhomogeneous packing of the capillaries. 
other than those belonging to struvite were observed at any intermediate time step.

Fig. 5B shows the corresponding time-resolved SAXS patterns of the thermally treated struvite powders over the $q$-range where the maximum observable feature length-scale is $\sim 120 \mathrm{~nm}$ (diameter). For untreated several micron-sized struvite crystals (Fig. 1A) one would expect a scattering pattern following a $I(q) \propto A q^{-4}$ dependence (dotted line in Fig. 5B) extending to high- $q$. In this relationship $A$ is a constant proportional to the product of the surface area of the scattering features and the scattering contrast ${ }^{32}$ (i.e., the square of the electron density difference between the material and the surrounding medium/matrix). Such a scattering pattern originates from the interface between the crystal and the matrix (air). Indeed our powders that were analysed by SAXS just 5 minutes after initiation of thermal treatment were characterized by such a scattering pattern (Fig. 5B). With increasing thermal treatment time we observed that for $q<0.02 \AA^{-1}$ the overall scattering intensity gradually increases by a factor of $\sim 5$, while the scattering exponent remains constant. We attribute this overall change primarily to the progressive increase in the material's surface area. At the same time for $q>0.02 \AA^{-1}$ it can be seen that the $A q^{-4}$ dependence is no longer followed and the scattering patterns contain features attributable to nano-sized morphologies. For the patterns collected after 10 and $20 \mathrm{~min}$ thermal treatment the observed features are difficult to interpret. In contrast, the high- $q$ part of the curves after 20 min contains clear correlation peaks (the $1^{\text {st }}$ maximum at $\sim 0.1 \AA^{-1}$ and the $2^{\text {nd }}$ at $\sim 0.21 \AA^{-1}$, see Fig. $5 \mathrm{~B}$ ). These maxima originate from structure factor inter-feature interferences and we attribute such scattering features to nano-sized pores forming within the bulk of the material. This corroborates our observations documented above through the changes in gas adsorption characteristics (Fig. 4). The shape of the correlation peaks in the 20 min SAXS patterns point to a relatively regular pore shape, and close geometric proximity as the cause of the observed interference. Patterns collected after 40 minutes revealed a relatively constant overall shape of the scattering feature, suggesting that the regularly-shaped and relatively monodisperse pores were already formed at 40 minutes and the increase in intensity in this part of $q$ is related to the increasing population of those pores. This matches the pore volume data from gas adsorption (Fig. 4C) where the majority of the change was also over after 40 minutes and absolutely no more change was observed after 80 minutes. From the SAXS data (Fig. 5B), the exact position of the $1^{\text {st }}$ maximum, $q_{\text {max }}$, and the relationship

$$
d \approx 2 \pi / q_{\max }
$$

yields an approximate equivalent diameter of $\sim 5-6 \mathrm{~nm}$ for the pore diameters. Furthermore, we modelled the scattering data collected after $160 \mathrm{~min}$ of thermal treatment under the assumption that the pores where spherical in shape, polydisperse in size and interacted through a hard-sphere potential to represent the high- $q$ correlations. The model (Fig. 5B, broad purple line) did not reproduce well the position of the $2^{\text {nd }}$ maximum and also somewhat deviated from the complete profile of the $1^{\text {st }}$ maximum. This discrepancy indicates that the pores were relatively monodisperse, but not spherical in shape. However, the model reproduced the two major scattering maxima, from which we could derive an average pore diameter of $\sim 5.2 \mathrm{~nm}$. This value is somewhat larger than the one obtained from the $\mathrm{N}_{2}$ gas adsorption measurements (3.1-3.2 nm; Fig. 4 and Table 1), but this can likely be explained because the spherical model of the SAXS data overestimates diameters for cylindrical pores, while the BJH derived average pore widths from the $\mathrm{N}_{2}$ gas adsorption measurements underestimates the pore size by up to $30 \%$.

We also carried out in situ and time-resolved SAXS measurements of a struvite sample heated to only $40^{\circ} \mathrm{C}$, but at a lower pressure of $1 \mathrm{mbar}$. Under these conditions, we only observed a single peak at $q \sim 0.2 \AA^{-1}$ (Fig. S7 $\dagger$ ) suggesting a different, more disordered mesoporous structure compared to the one that formed at $90^{\circ} \mathrm{C}$ and ambient pressure.

\subsection{A new strategy for synthesizing mesoporous phosphates}

Mesostructured phosphates have been extensively studied for their unique properties and great potential applications, particularly in biomedicine and catalysis. ${ }^{10-18}$ However, although various mesoporous phosphates have been documented in the literature, their synthesis is still fraught by several problems and limitations. Present strategies for the synthesis of mesoporous phosphates are based largely on the use of organic templates. Such templating strategies have proven to be very successful for the preparation of mesoporous silica, but present great difficulties for phosphates. Partly, these difficulties are due to the more rapid hydrolysis and condensation processes in metal-phosphate systems. This often results in fast precipitation and thus less interaction between the organic template and the inorganic metal/phosphate precursors. Another problem relates to the subsequent removal of the organic template. While calcination at high temperatures or treatment with strong acids often leads to severe degradation of the mesoporous phosphate structure, milder extraction methods usually result in incomplete removal of the often harmful organic species. For these reasons, there are only few reports on the shape and size-controlled synthesis of phosphates with well-defined mesoporous structures. ${ }^{15}$ Moreover, until now, the synthesis of porous phosphates has been confined mainly to zirconium and titanium phosphates, while other mesoporous metal phosphates have been only sporadically reported.

In this study, we developed a template-free strategy for the synthesis of a mesoporous Mg-phosphate based on the pseudomorphic thermal decomposition of a crystalline struvite precursor. Our results show that this thermal decomposition strategy is well-controllable and -reproducible. Compared to current template-based synthesis routes it combines several other advantages. Firstly, the synthesis of struvite is a straightforward process that only involves the mixing of magnesium and phosphate solutions at ambient temperature and pressure 

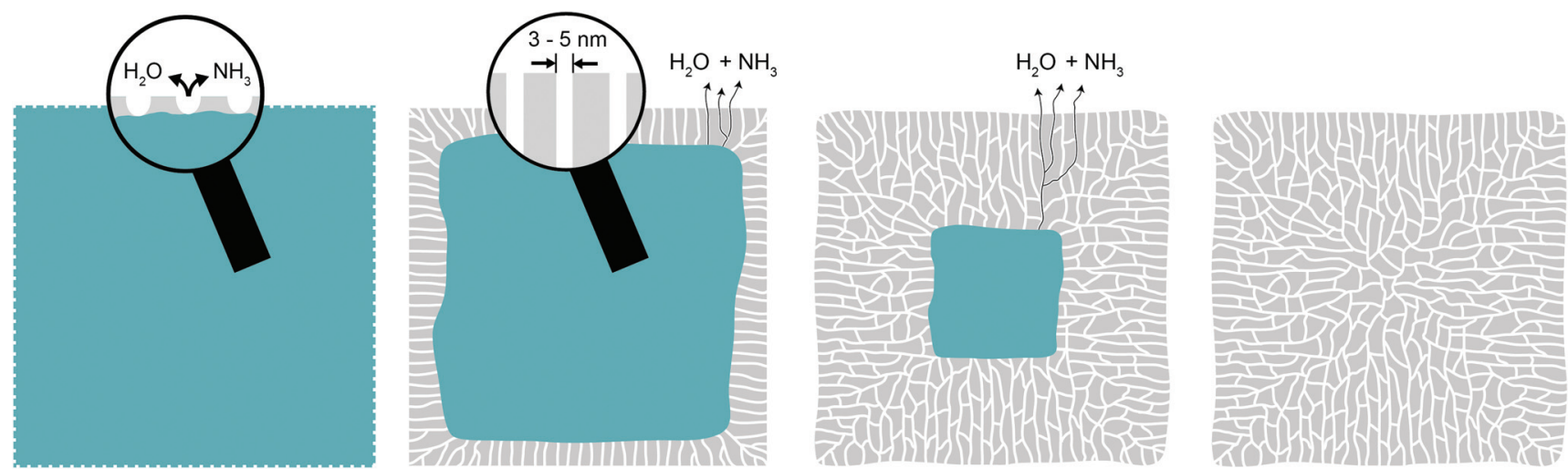

\section{crystalline struvite amorphous Mg-phosphate}

$\mathrm{S}_{\mathrm{BET}}(\max ) \approx 300 \mathrm{~m}^{2} / \mathrm{g}$

$\mathrm{V}_{\text {pore }}(\max ) \approx 0.28 \mathrm{~cm}^{3} / \mathrm{g}$

\section{mass loss / pore volume / surface area}

Fig. 6 Schematic illustration of the struvite decomposition process.

conditions. This process is also expected to have a good scaleup potential, especially considering that struvite can even be synthesized from agricultural and industrial waste waters. ${ }^{33}$ The morphology and size of the struvite precursor (and thus the final mesoporous product) can be varied by simply changing synthesis parameters such as concentration, $\mathrm{pH}$ or solution mixing dynamics. Here, we show that crystals with various morphologies (i.e., dendritic, X-shaped; blocky, coffin-lid shaped; elongated, lath-shaped) and sizes ranging from just a few micrometres to several millimetres can be easily prepared (Fig. 1). Thermal decomposition of this struvite precursor already starts at temperatures well below $100{ }^{\circ} \mathrm{C}$, so that calcination at high temperatures is also not required. This also makes the process very energy efficient. Under vacuum decomposition occurs at temperatures even below $50{ }^{\circ} \mathrm{C}$, but leads to a different, more disordered mesoporous structure (Fig. S7†). Therefore, a combined heat and low pressure treatment could thus possibly be used to tailor the pore size distributions of the final material over a broader range. Finally, this synthesis and decomposition strategy could readily be transferred to other porous phosphates since struvite can accept a wide range of substitutes within its $\mathrm{M} 1 \mathrm{M} 2 \mathrm{~A} \cdot 6 \mathrm{H}_{2} \mathrm{O}$ structure (M1: $\mathrm{NH}_{4}^{+}, \mathrm{K}^{+}, \mathrm{Rb}^{+}, \mathrm{Cs}^{+}, \mathrm{Tl}^{+} ; \mathrm{M} 2: \mathrm{Mg}^{2+}, \mathrm{Ni}^{2+}, \mathrm{Zn}^{2+}, \mathrm{Co}^{2+}, \mathrm{Cd}^{2+}$, $\left.\mathrm{Cr}^{3+}, \mathrm{Mn}^{2+}, \mathrm{VO}^{2+} ; \mathrm{A}: \mathrm{PO}_{4}{ }^{3-}, \mathrm{AsO}_{4}{ }^{3-}\right) .{ }^{34-41}$ In this regard, the incorporation of transition metals could lead to a range of materials for applications in the field of catalysis. ${ }^{15-18}$

The material described in this work has one of the largest surface areas $\left(300 \mathrm{~m}^{2} \mathrm{~g}^{-1}\right)$ and narrowest pore size distributions $(2-5 \mathrm{~nm})$ ever reported for a mesoporous phosphate. ${ }^{15}$ This material could become useful for biomedical applications considering that it is composed of Mg-phosphate - a non-toxic compound that has already shown high biocompatibility and degradability. ${ }^{42,43}$ In particular, it may be of interest for the development of new drug delivery systems where narrow pore size distributions are indispensable for homogenous drug loading and precise control of drug release rates. ${ }^{7}$

\section{Summary and conclusions}

Herein we show that the thermal decomposition of struvite at temperatures below $100{ }^{\circ} \mathrm{C}$ leads to a pseudomorphic transformation into a mesoporous Mg-phosphate featuring a welldefined pore structure and high surface area. Based on the presented results, the following formation process (Fig. 6) can be proposed: In the beginning, small pores start to nucleate at the external surfaces of the struvite crystal due to the removal of structurally bound water and ammonia. This is accompanied by a localized collapse of the crystalline structure (amorphization). Subsequently, the pores start to deepen without growing in width resulting in relatively uniform, channel-like pores with a very narrow size distribution between $2-5 \mathrm{~nm}$. At the same time, water and ammonia are continuously released through the pore channels from a retreating crystalline-amorphous interface. This process continues until the struvite crystal is fully transformed into the amorphous Mg-phosphate phase leaving behind a porous network with a high specific surface area $\left(\sim 300 \mathrm{~m}^{2} \mathrm{~g}^{-1}\right)$ and pore volume $\left(0.28 \mathrm{~cm}^{3} \mathrm{~g}^{-1}\right)$. The presented synthesis procedure could provide a basis for the development of advanced functional phosphate-based materials for various applications in biomedicine and catalysis.

\section{Note}

The information contained in this paper is patent pending (European Patent Application no. EP18158825.2). 


\section{Conflicts of interest}

There are no conflicts of interest to declare.

\section{Acknowledgements}

L. G. B., J. H., T. M. S., R. B., H. M. F. and S. M. acknowledge the financial support of the Helmholtz Recruiting Initiative (Award No. I-044-16-01). We thank Diamond Light Source for access to beamline I22 through a grant to T. M. S, L. G. B., J. H. and R. B. This research was partially supported by a Marie Curie grant from the European Commission in the framework of the NanoSiAl Individual Fellowship (Project No. 703015) to T. M. S. and a Scientific Network grant from the German Research Council (DFG) (Project No. 389508713) to H. M. F. L. G. B. and K. M. D. also acknowledge funding received through the European Union's Horizon 2020 Marie Skłodowska-Curie Innovative Training Network Metal-Aid (Project No. 675219). We thank our GFZ colleagues Judith Schicks for her help with the Raman analyses, Anja Schleicher for her help with the XRD analyses and Anja Schreiber for the preparation of the FIB sections.

\section{References}

1 IUPAC - International Union of Pure and Applied Chemistry, https://iupac.org/.

2 A. Corma, From Microporous to Mesoporous Molecular Sieve Materials and Their Use in Catalysis, Chem. Rev., 1997, 97(6), 2373-2420.

3 Z. Wu and D. Zhao, Ordered Mesoporous Materials as Adsorbents, Chem. Commun., 2011, 47(12), 3332.

4 M. Tiemann, Porous Metal Oxides as Gas Sensors, Chem. Eur. J., 2007, 13(30), 8376-8388.

5 F. Cheng, Z. Tao, J. Liang and J. Chen, Template-Directed Materials for Rechargeable Lithium-Ion, Society, 2007, 667681.

6 O. Hernandez-Ramirez and S. M. Holmes, Novel and Modified Materials for Wastewater Treatment Applications, J. Mater. Chem., 2008, 18(24), 2751-2761.

7 M. Vallet-Regí, Ordered Mesoporous Materials in the Context of Drug Delivery Systems and Bone Tissue Engineering, Chem. - Eur. J., 2006, 12(23), 5934-5943.

8 T. Asefa and V. Dubovoy, Ordered Mesoporous/Nanoporous Inorganic Materials via Self-Assembly, Elsevier, 2nd edn, 2017, vol. 9.

9 C. T. Kresge, M. E. Leonowicz, W. J. Roth, J. C. Vartuli and J. S. Beck, Ordered Mesoporous Molecular Sieves Synthesized by a Liquid-Crystal Template Mechanism, Nature, 1992, 359, 710-712.

10 J. Yao, W. Tjandra, Y. Z. Chen, K. C. Tam, J. Ma and B. Soh, Hydroxyapatite Nanostructure Material Derived Using Cationic Surfactant as a Template, J. Mater. Chem., 2003, 13(12), 3053.
11 T. Peltola, M. Jokinen, H. Rahiala, E. Levanen, J. B. Rosenholm, I. Kangasniemi and A. Yli-Urpo, Calcium Phosphate Formation on Porous Sol-Gel-Derived SiO2 and CaO- P2O5-SiO2 Substrates in Vitro, J. Biomed. Mater. Res., 1998, 44(1), 12-21.

12 J. Zhang, M. Fujiwara, Q. Xu, Y. Zhu, M. Iwasa and D. Jiang, Synthesis of Mesoporous Calcium Phosphate Using Hybrid Templates, Microporous Mesoporous Mater., 2008, 111(1-3), 411-416.

13 P. J. T. Reardon, J. Huang and J. Tang, Mesoporous Calcium Phosphate Bionanomaterials with Controlled Morphology by an Energy-Efficient Microwave Method, J. Biomed. Mater. Res., Part A, 2015, 103(12), 3781-3789.

14 O. G. da Silva, M. M. Alves, I. M. G. dos Santos, M. G. Fonseca and M. Jaber, Mesoporous Calcium Phosphate Using Casein as a Template: Application to Bovine Serum Albumin Sorption, Colloids Surf., B, 2017, 158, 480-487.

15 R. Lin and Y. Ding, A Review on the Synthesis and Applications of Mesostructured Transition Metal Phosphates, Materials, 2013, 6(1), 217-243.

16 B. Tian, X. Liu, B. Tu, C. Yu, J. Fan, L. Wang, S. Xie, G. D. Stucky and D. Zhao, Self-Adjusted Synthesis of Ordered Stable Mesoporous Minerals by Acid-base Pairs, Nat. Mater., 2003, 2(3), 159-163.

17 M. Pramanik, J. Lee, S. Tominaka, Y. Ide, J. H. Kim and Y. Yamauchi, Unique Nanocrystalline Frameworks in Mesoporous Tin Phosphate Prepared through a Hydro Fl Uoric Acid Assisted Chemical Reaction $\dagger, J$. Mater. Chem. A, 2016, 1-9.

18 M. Pramanik, C. Li, M. Imura, V. Malgras, Y. M. Kang and Y. Yamauchi, Ordered Mesoporous Cobalt Phosphate with Crystallized Walls toward Highly Active Water Oxidation Electrocatalysts, Small, 2016, 12(13), 1709-1715.

19 M. I. H. Bhuiyan, D. S. Mavinic and F. A. Koch, Thermal Decomposition of Struvite and Its Phase Transition, Chemosphere, 2008, 70(8), 1347-1356.

20 M. V. Ramlogan and A. A. Rouff, An Investigation of the Thermal Behavior of Magnesium Ammonium Phosphate Hexahydrate, J. Therm. Anal. Calorim., 2016, 123(1), 145152.

21 A. K. Sarkar, Hydration/Dehydration Characteristics of Struvite and Dittmarite Pertaining to Magnesium Ammonium Phosphate Cement Systems, J. Mater. Sci., 1991, 26(9), 2514-2518.

22 G. Kurtulus and A. C. Tas, Transformations of Neat and Heated Struvite (MgNH4PO 4.6H2O), Mater. Lett., 2011, 65(19-20), 2883-2886.

23 B. Lafuente, R. T. Downs, H. Yang and N. Stone, The Power of Databases: The RRUFF Project, in Highlights in Mineralogical Crystallography, Walter de Gruyter $\mathrm{GmbH}$, Berlin, Germany, 2016.

24 B. R. Pauw, A. J. Smith, T. Snow, N. J. Terrill and A. F. Thünemann, The Modular Small-Angle X-Ray Scattering Data Correction Sequence, J. Appl. Crystallogr., 2017, 50(6), 1800-1811. 
25 R. J. C. Mclean, J. Downey, L. Clapham and J. C. Nickel, A Simple Technique for Studying Struvite Crystal Growth in Vitro, Urol. Res., 1990, 18, 39-43.

26 M. Thommes, Physical Adsorption Characterization of Nanoporous Materials, Chem.-Ing.-Tech., 2010, 82(7), 10591073.

27 A. V. Neimark, P. I. Ravikovitch and A. Vishnyakov, Adsorption Hysteresis in Nanopores, Phys. Rev. E: Stat. Phys., Plasmas, Fluids, Relat. Interdiscip. Top., 2000, 62(2), R1493-R1496.

28 C. G. Sonwane and S. K. Bhatia, Characterization of Pore Size Distributions of Mesoporous Materials from Adsorption Isotherms, J. Phys. Chem. B, 2000, 104(39), 9099-9110.

29 A. V. Neimark, P. I. Ravikovitch, M. Grün, F. Schüth and K. K. Unger, Pore Size Analysis of MCM-41 Type Adsorbents by Means of Nitrogen and Argon Adsorption, J. Colloid Interface Sci., 1998, 207(1), 159-169.

30 P. L. Llewellyn, Y. Grillet, F. Schüth, H. Reichert and K. K. Unger, Effect of Pore Size on Adsorbate Condensation and Hysteresis within a Potential Model Adsorbent: M41S, Microporous Mater., 1994, 3(3), 345-349.

31 J. C. Groen, L. A. A. Peffer and J. Pérez-Ramírez, Pore Size Determination in Modified Micro- and Mesoporous Materials. Pitfalls and Limitations in Gas Adsorption Data Analysis, Microporous Mesoporous Mater., 2003, 60(1-3), 1-17.

32 R. Besselink, T. M. Stawski, A. E. S. Van Driessche and L. G. Benning, Not Just Fractal Surfaces, but Surface Fractal Aggregates: Derivation of the Expression for the Structure Factor and Its Applications, J. Chem. Phys., 2016, 145(21), 211908.

33 S. Kataki, H. West, M. Clarke and D. C. Baruah, Phosphorus Recovery as Struvite from Farm, Municipal and Industrial Waste: Feedstock Suitability, Methods and PreTreatments, Waste Manag., 2016, 49, 437-454.

34 H. Basset and W. L. Bedwell, Studies of Phosphates. Part I. Ammonium Magnesium Phosphate and Related Compounds, J. Chem. Soc., 1933, 854-871.

35 E. Banks, R. Chianelli and R. Korenstein, Crystal Chemistry of Struvite Analogs of the Type MgMPO4.6H2O (M+ = K+, Rb+, Cs+, Ti+, NH4+), Inorg. Chem., 1975, 14(7), 1634-1639.
36 V. Stefov, B. Šoptrajanov, F. Spirovski, I. Kuzmanovski, H. D. Lutz and B. Engelen, Infrared and Raman Spectra of Magnesium Ammonium Phosphate Hexahydrate (Struvite) and Its Isomorphous Analogues. I. Spectra of Protiated and Partially Deuterated Magnesium Potassium Phosphate Hexahydrate, J. Mol. Struct., 2004, 689, 1-10.

37 V. Stefov, B. Soptrajanov, M. Najdoski, B. Engelen and H. D. Lutz, Infrared and Raman Spectra of Magnesium Ammonium Phosphate Hexahydrate (Struvite) and Its Isomorphous Analogues. V. Spectra of Protiated and Partially Deuterated Magnesium Ammonium Arsenate Hexahydrate (Arsenstruvite), J. Mol. Struct., 2008, 872, 87-92.

38 R. V. S. S. N. Ravikumar, S. N. Rao, B. J. Reddy and Y. P. Reddy, Electronic Spectra of Hexa Aqua Coordinated Transition Metal Doped Zinc Struvite, Ferroelectrics, 1996, 189(1-4), 139-147.

39 R. V. S. S. N. Ravikumar, A. V. Chandrasekhar, S. N. Rao, N. Madhu, B. J. Reddy and Y. P. Reddy, Orthorhombic Site Symmetry of $\mathrm{Cr} 3+$ in ZnNH4 PO4 6H2 O Crystals, Cryst. Res. Technol., 1999, 34, 911-914.

40 R. V. S. S. N. Ravikumar, A. V. Chandrasekhar, B. J. Reddy, Y. P. Reddy and K. Ikeda, X-Ray Powder Diffraction, DTA and Vibrational Studies of CdNH4PO4.6H2O Crystals, Cryst. Res. Technol., 2002, 37(10), 1127-1132.

41 P. Chand and O. P. Agarwal, Electron Paramagnetic Resonance Study of Doped Synthetic Crystals of Struvite and Its Zinc Analogue, Spectrochim. Acta, Part A, 1991, 47(6), 775-783.

42 Y. Yu, J. Wang, C. Liu, B. Zhang, H. Chen, H. Guo, G. Zhong, W. Qu, S. Jiang and H. Huang, Evaluation of Inherent Toxicology and Biocompatibility of Magnesium Phosphate Bone Cement, Colloids Surf., B, 2010, 76(2), 496-504.

43 F. Tamimi, D. L. Nihouannen, D. C. Bassett, S. Ibasco, U. Gbureck, J. Knowles, A. Wright, A. Flynn, S. V. Komarova and J. E. Barralet, Biocompatibility of Magnesium Phosphate Minerals and Their Stability under Physiological Conditions, Acta Biomater., 2011, 7(6), 26782685. 